\begin{tabular}{ccc}
\hline International Journal of Advanced Astronomy, $7(1)(2019) 15-16$ \\
SPC \\
Website: www.sciencepubco.com/index.php/IJAA \\
Research paper
\end{tabular}

\title{
Theory of gateway in case of time travel
}

\author{
Sahriar Ahamed * \\ Gollamari North Bank Khal Road, Khulna, Bangladesh \\ *Corresponding author E-mail: ahamedsahriar@gmail.com
}

\begin{abstract}
When we record any video, where do we keep and store it? In a space- that we call memory card or disk or any other kind of storage device. When we are required to see our memories, what we do? We play it with a video player software which is known as media player, dvd player or video player etc. These video player software works as the gate way to visualize the past in-front of us. Same way our reality is storing in another place/space which is another dimension that we know as our past. We can always see it by creating a gate way same as video player software or we may say it as knowledge.
\end{abstract}

Keywords: Time; Space; Relativity; Albert Einstein; Light; Speed of Rays; Gate Way; Travel Time; String Theory.

\section{Introduction}

Assumption: We can't see the past/future by travelling 3-dimensional space. Logic of assumption: We see reality and particles due to the color. Colors are nothing but some combination of rays. The thing doesn't reflect color we can't see it. So, Firstly, the reflection of color is not the complete real thing. Truth is, in space only the reflected color is possible to exist from the real physical body. The threedimensional universe is not presenting one thing many times. So, by physical existences one thing is possible to have only one existence. So, by travelling space we can't see real thing with physical body in any other different place. According to the rules of Albert Einstein, "One thing cannot exist in two different states at the same time" there is no such thing exists in space in two states at the same time no matter it is past or future or present. [1] So, by traveling at space we can't see our past or duplicate me or any one or thing of past or future. I was existing only one state I am existing at this moment and I shall exist in one state too.

\section{Decision}

In this space I am existing as only one. So, it's not possible to see another me by traveling this $3^{\text {rd }}$ dimensional space.

Second Observation of assumption: Even though, we presume somehow if we go at the speed of light, we can get the passport of watching the past. [2] But truth is, rays speed varies in space. [3] So, different visible colors and rays will not reach to a certain place at the same time say 10,000/20000 light years distance. The fastest rays and its visible part will reach first and the slowest rays and its visible part will reach later. Thus, even after we achieve the speed of light, we can't see the total thing after crossing a particular distance. So, after getting the Physical existence of anything of 10,000/20,000 light year we can't see it properly due to variation of rays speed. So, by going at the speed of light we can't see the past or future at all. More over light is traveling with us in the space. Its photons are not going another dimension nor traveling another dimension also. The light arises and comes from different media; travels with us in this 3dimensional world. [4].

\section{Confirmation decision}

for Assumption: So, from above logics we can come to our decision that - "Even after getting more speed than light we can't see the past/future due to logical reason by travelling this $3^{\text {rd }}$ dimensional space."

Now question is, "Then how it's possible to see the past or future?".

\section{Proposed theory of travelling time}

Did we notice that the nature is maintaining a highly technical and scientific rules? Indeed the nature or creator of us is running the universe according to a highly technological and scientific rules and regulation. Nature is the best teacher. [5] So, it is teaching us technology to human also. Thus, human is flying by jet plane, lighting up the society with electric light, running cars and making videos of his past. While we video with a camera how we store the memories in camera? All the memories are stored in a place/space/memory card/pen drive/CD drive or somewhere like this as a database file. [6] 
How do we look it again? We just play a video player/media player - A Software. This software works as a gate way to show us the recorded data. [7] Actually, in case of camera we can see only the data as different colors. Not the real thing with its physical existence. We see only the colors of the physical existences.

In case of reality we are watching both the colors with physical existences. Actually, our future is arising in to a dimension. It passes through the 3(three) dimensional space which we are observing during our life time with our eyes. Same as we see the movie in a cinema hall. It is passing in-front of our eyes without giving any time. Thus, the present is getting past within the same momentum. From the other dimension it will look like that the present is becoming visible with in zero hour and will become past in zero hour too. It is getting stored in to somewhere in another dimension known as past. With right kind of security. [8]

If we take a look, we may see that time has a positive and negative face. It works like an electricity supply in a house or office- with a positive and negative face and becoming neutrals at a position or the condition of PRESNT of time. [9]

\section{Significances of theory of gateway}

So, if we analyze the space from the above point of view, we may see that

1) There is no use travelling the space to see the past or future

2) Light, material, spirit, visible, invisible everything is included or part of the 3 dimension. All these thing are making and helping to run this universe.

3) Only the multidimensional knowledge can help us to travel dimension and see the past and future. Due to segment of dimensions we need to have knowledge to create and open the gate way for traveling dimension.

\section{Decision}

So, based on the above logic and argument, my theory is that a gate way can help us to look through in to past or future. And to achieve these gate ways creation knowledge we need to have some certain knowledge as Depth Knowledge of Time, Depth Knowledge of OUR PHISICAL EXISTANCES of living animal bodies. I have shown an example to analyze the time in my book "Theory OF relativity of time and of evaluation of Human Civilization". [10]

We can analyze our physical body also in many ways. Our physical body is divided into many parts according to functionality. Some theorist of YOUGA specialists/doctors had done it already in scientific and logical way. We can analyze the physical existence in to more scientific terms on aspect of traveling time. It can follow a theory is known as String Theory. This String Theory can explain how our physical body can be replaced by one dimensional object as well.[11].

Thus, at the end I like to say that only the depth analysis and knowledge can show us that by creating a gateway we can travel time and dimension.

\section{References}

[1] https://www.independent.co.uk/news/science/einstein-was-right-you-can-be-in-two-places-at-once-2162648.html.

[2] http://www.pbs.org/wgbh/nova/blogs/physics/2015/08/can-you-really-go-back-in-time-by-breaking-the-speed-of-light/

[3] http://www.oasisllc.com/abgx/radioactivity.htm.

[4] https://sciencing.com/light-travel-4570255.html.

[5] https://www.huffingtonpost.com/karalyne-martinez/nature-is-the-best-teache b $9803412 . h t m l$.

[6] https://www.mongodb.com/blog/post/storing-large-objects-and-files-in-mongodb.

[7] https://www.techwalla.com/articles/how-to-play-mpg-file-in-window-media-player.

[8] https://www.linkedin.com/pulse/news-science-world-time-travel-past-possible-sahriar-ahamed.

[9] https://www.linkedin.com/pulse/another-view-time-sahriar-ahamed/.

[10] https://www.morebooks.de/store/gb/book/theory-of-relativity-of-time-and-of-evaluation-of-human-civilization/isbn/978-3-659-75070-0.

[11] https://www.britannica.com/science/string-theory. 